\title{
Otomasi Penerangan Laboratorium berdasarkan Aktivitas Manusia
}

\section{IVANY SARIEF ${ }^{1}$, USMAN SARTOYO ${ }^{2}$, DADANG KURNIA ${ }^{3}$, CECEP SUBAGJA4, ALDO GERALDI DJATNIKA ${ }^{5}$, ANDIKA PRATAMA ${ }^{6}$}

\author{
1,3,4,5,6 Program Studi Teknik Elektro - Fakultas Teknik \\ Universitas Sangga Buana YPKP \\ 2Universitas Kebangsaan Republik Indonesia \\ Email: ivansarief@gmail.com
}

Received 18 Juli 2019 | Revised 7 Agustus 2019 | Accepted 27 Agustus 2019

\begin{abstract}
ABSTRAK
Energi listrik menjadi kebutuhan penting dalam kehidupan. Ketergantungan manusia terhadap energi listrik dewasa ini terus meningkat, sehingga manusia dituntut untuk melakukan penghematan dalam pemakaian energi listrik. Oleh karena itu otomatisasi perlatan listrik diperlukan, guna menghindari pemborosan energi listrik. Desain otomasi ini terdiri dari sensor Passive Infrared Receiver (PIR) yang berfungsi sebagai pendeteksi aktivitas manusia, sensor Light Dependent Resistor (LDR) yang berfungsi sebagai pendeteksi cahaya, dan kontroler sebagai pengendali jalannya sistem otomasi ini. Sistem yang di implemasikan mampu menghidupkan dan mematikan lampu ruangan secara otomatis berdasarkan keberadaan manusia dengan luas jangkauan sensor PIR HC-SR501 sejauh 365,3 $\mathrm{cm}^{2} /$ sensor.
\end{abstract}

Kata kunci; Energi listrik, Laboratorium, sensor PIR, sensor LDR, Kontroler

\begin{abstract}
Electrical energy is an important requirement in life. Human dependence on electrical energy today continues to increase, so humans are required to make savings in the use of electrical energy. Therefore, the automation of electrical equipment is needed, to avoid wasting electricity. The design of this automation consists of a Passive Infrared Receiver (PIR) sensor that functions as a detector of human activity, a Light Dependent Resistor (LDR) sensor that functions as a light detector, and a controller as a controller for the running of this automation system. The implemented system can turn on and turn off room lights automatically based on human presence with a wide range of HC-SR501 PIR sensors as far as 365.3 $\mathrm{cm} 2$ / sensor.
\end{abstract}

Keyword: Electrical energy, Laboratory, sensor PIR, sensor LDR, controller 


\section{PENDAhUlUAN}

Laboratorium merupakan sarana pendukung yang strategis dalam sistem pendidikan. Dalam perguruan tinggi laboratorium diperlukan untuk menunjang akademik dalam kegiatan penelitian maupun pengabdian kepada masyarakat. Kebutuhan penggunaan energi listrik bagi aktivitas laboratorium adalah sebuah keniscayaan. Tanpa adanya energi listrik, mahasiswa tidak akan mampu melakukan aktivitas di laboratorium. Begitu pentingnya peranan energi listrik tersebut, diperlukan adanya regulasi yang mengatur dengan jelas dan lugas terkait tata kelola penggunaan energi listrik. Disinilah peran institusi atau manajemen untuk membuat dan menegakkan regulasi tentang penggunaan energi listrik. Di sisi lain, laboratorium dituntut untuk menghasilkan karya sesuai misinya, namun seperti bisnis lainnya, efisiensi energi listrik mempengaruhi produk dan mutu yang akan diraih. Dihadapkan dengan standar ganda dalam mengurangi pemborosan energi listrik dan mematuhi persyaratan dari regulasi yang ketat adalah beban unik dari para pimpinan laboratorium. Pimpinan laboratorium menyadari akan meningkatnya kebutuhan terhadap efisiensi energi listrik, namun kesulitan dalam memulai perubahan, sebagian karena kebanyakan laboratorium tidak memiliki metode baku dalam mengurangi penggunaan dan biaya energi listrik (Sutono, 2015).

Laboratorium dapat meningkatkan penghematan energi tanpa mengorbankan standar ketaatan atau standar keselamatan. Beberapa hal yang dapat dilakukan diantaranya: melakukan audit dan pengukuran penggunaan energi, memperbaiki hal yang mendasar, melakukan optimasi melalui otomasi dan regulasi, melakukan pengawasan dan pemeliharaan untuk perbaikan terus menerus. Tujuan penelitian ini didasarkan pada aktivitas manusia dengan mempertimbangkan intensitas cahaya di dalam ruangan, sehingga dapat membantu penghematan penggunaan energi listrik di Universitas Sangga Buana YPKP.

Rancang bangun alat terbatas pada perancangan sistem otomasi penerangan ruang laboratorium teknik elektro berdasarkan aktivitas manusia dengan mempertimbangkan intensitas cahaya di dalam ruangan. Aktivitas manusia diindra berdasarkan pola gerak tubuh menggunakan sensor Passive Infrared Receiver (PIR), dan sensor Light Dependent Resistor (LDR) sebagai pendeteksi cahaya. Audit energi tidak dilakukan secara menyeluruh ke seluruh gedung, namun hanya dilakukan pada laboratorium Teknik Elektro Universitas Sangga Buana YPKP saja (Fallo, 2017).

\section{PEMBAHASAN}

Perancangan otomasi penerangan ruang laboratorium Teknik Elektro Universitas Sangga Buana YPKP ini diharapkan mampu membantu penghematan penggunaan energi listrik. Sistem yang akan dibuat ini menggunakan beberapa komponen, yang diantaranya adalah sensor PIR untuk mendeteksi aktivitas manusia dan sensor LDR sebagai pendeteksi cahaya.

\subsection{Sensor Passive Infrared Receiver (PIR)}

Sensor yang berbasis infrared berbeda dengan fototransistor atau IR-LED (Infrared Light Emitting Diode). Sensor PIR merespon energi dari pancaran infrared pasif yang dimiliki oleh setiap benda yang terdeteksi, dengan suhu benda di atas nol. Pancaran infrared inilah yang 
kemudian ditangkap oleh pyroelectric sensor yang merupakan inti dari sensor PIR, sehingga menyebabkan pyroelectic sensor yang terdiri dari galliumnitride, caesium nitrate dan lithiumtantalate menghasilkan arus listrik. Maka, ketika seseorang melewati sensor, sensor akan menangkap pancaran infrared pasif yang dipancarkan oleh tubuh manusia yang memiliki suhu yang berbeda dari lingkungan sekitar sehingga menyebabkan material pyroelectric bereaksi menghasilkan arus listrik karena adanya energi panas yang dibawa oleh infrared pasif tersebut (Toyib, Bustami and Abdullah, 2019). Setelah itu sirkuit amplifier menguatkan arus tersebut yang kemudian dibandingkan oleh comparator sehingga menghasilkan output.

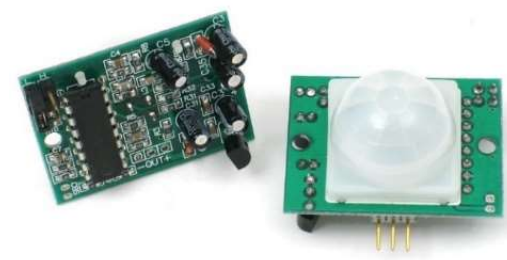

\section{Gambar 1. Modul Sensor PIR}

Di dalam sensor PIR ini terdapat beberapa bagian yang mempunyai peran masing-masing, yaitu: FresnelLens, IR Filter, Pyroelectric Sensor, Amplifier, dan Comparator. Seperti terlihat pada Gambar di bawah ini.

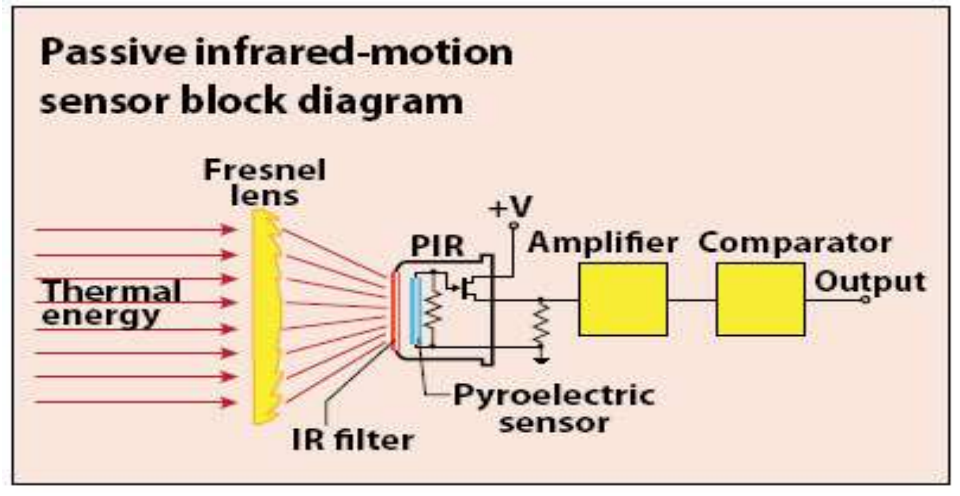

Gambar 2. Blok Diagram Sensor PIR

Modul sensor PIR ini memiliki beberapa pin, dan fungsi dari pin modul sensor PIR.

Tabel 1. Fungsi Pin Modul Sensor PIR

\begin{tabular}{|l|l|}
\hline PIN & FUNGSI \\
\hline VCC & Sumber tegangan \\
\hline GND & Ground \\
\hline OUT & $\begin{array}{l}\text { Output (berlogika high } \\
\text { dan low) }\end{array}$ \\
\hline
\end{tabular}




\subsection{Sensor Light Dependent Resistor (LDR)}

Salah satu komponen listrik yang peka terhadap cahaya, bisa disebut sebagai fotosel, fotokonduktif atau fotoresistor. Bahan semikonduktor pada LDR karakteristik listriknya dapat berubah-ubah sesuai cahaya yang diterima. Bahannya adalah KadmiumSulfida (CdS) dan KadmiumSelenida (CdSe). Dengan puncak sekitar $0.6 \mu \mathrm{m}$ untuk CdS dan 0,75 $\mu \mathrm{m}$ untuk CdSe bahannya paling sensitif terhadap cahaya. LDR CdS yang memiliki resistansi sekitar $1 \mathrm{M} \Omega$ dalam kondisi gelap dan kurang dari $1 \mathrm{~K} \Omega$ jika ditempatkan dibawah summber cahaya.

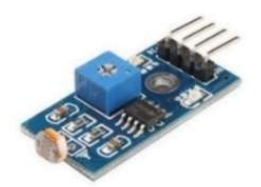

Gambar 3. Modul Sensor LDR

Karakteristik LDR terdiri atas dua macam.

\subsubsection{Laju Recovery}

Laju recovery merupakan suatu ukuran praktis dari nilai resistansi pada waktu tertentu. Sebuah LDR yang dibawa dari suatu ruangan dengan tingkat cahaya tertentu ke dalam ruangan yang gelap, dapat kita amati nilai resistansinya tidak akan segera berubah pada keadaan ruang yang gelap tersebut. LDR tersebut hanya akan mencapai harga di kegelapan setelah beberapa waktu. Harga ini ditulis dalam K/detik. LDR tipe arus harganya lebih besar dari $200 \mathrm{~K} /$ detik, kecepatan tersebut akan meninggi pada arah sebaliknya, yaitu dari tempat gelap ke tempat terang dengan waktu kurang dari 10 ms untuk mencapai resistansi yang sesuai dengan level cahaya 400 lux.

\subsubsection{Respon Spektral}

Sensitivitas yang dimiliki LDR tidak sama untuk setiap panjang gelombang cahaya yang jatuh padanya (warna). Bahan yang biasa digunakan sebagai penghantar arus listrik diantaranya tembaga, alumunium, baja, emas, dan perak. Bahan yang paling banyak digunakan adalah tembaga karena memiliki daya penghantar yang baik.

\subsection{Modul Relay}

Saklar (switch) yang dioperasikan secara elektrik dan komponen elektromekanikal terdapat 2 bagian utama yaitu elektromagnet (coil) dan mekanikal (switch). Dengan menggunakan elektromagnetik agar dapat menggerakan switch dengan arus listrik yang kecil (lowpower) menghantarkan listrik lebih tinggi.

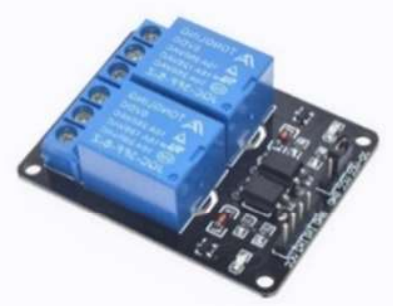

Gambar 4. Modul Relay 2 Channel 
Modul relay ini mempunyai 3 pin, dan fungsi dari pin modul relay ini dapat dilihat pada tabel

Tabel 2. Fungsi Pin Modul Relay

\begin{tabular}{|l|l|}
\hline PIN & FUNGSI \\
\hline VCC & Sumber tegangan \\
\hline GND & Ground \\
\hline IN & $\begin{array}{l}\text { Input untuk menerima data } \\
\text { (high dan low) }\end{array}$ \\
\hline
\end{tabular}

Sebelum masuk pada perancangan sistem, dalam penelitian ini terlebih dahulu membuat algoritma logika penyalaan lampu ruangan. Langkah ini bertujuan agar sistem yang dirancang sesuai dengan tujuan awal. Logika penyalaan lampu ruang dituangkan dalam bentuk flowchart seperti pada Gambar 5 di bawah ini:

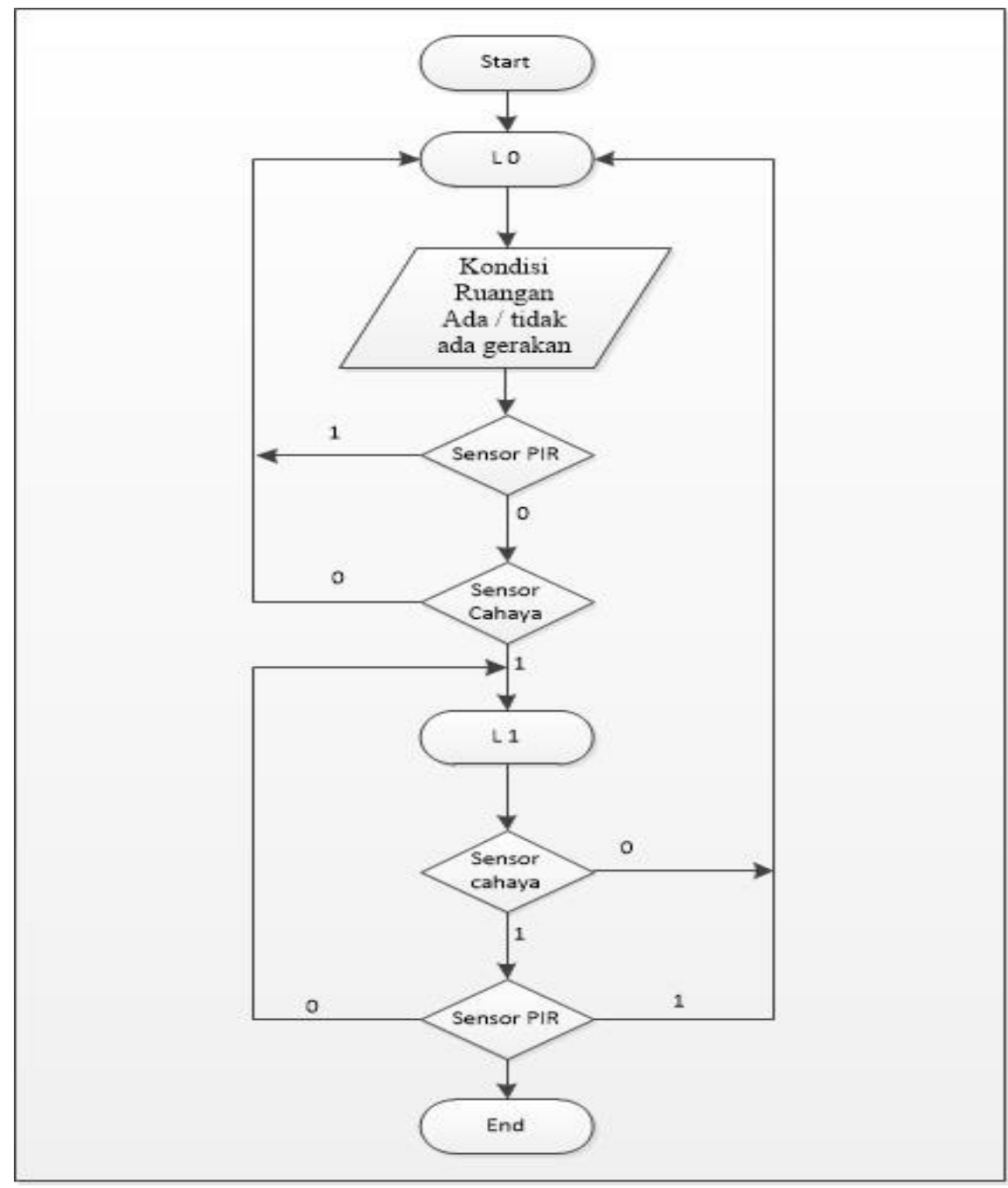

Gambar 5. Flowchart Logika Penyalaan Lampu

Mulai dari start kemudian kondisi ruangan yang akan dideteksi oleh sensor gerak, apakah di dalam rungan ada atau tidak ada gerakan, jika ada gerak maka alur akan diteruskan ke sensor MIND-84 
cahaya, kemudian sensor cahaya akan membaca apakah intensitas cahaya di dalam ruangan sudah memenuhi kebutuhan atau belum, jika belum maka lampu akan hidup dan jika sudah memenuhi kebutuhan maka lampu tetap padam.

\subsection{Sistem Secara Umum}

Sistem secara umum digambarkan dalam bentuk blok diagram, seperti terlihat pada gambar di bawah ini:

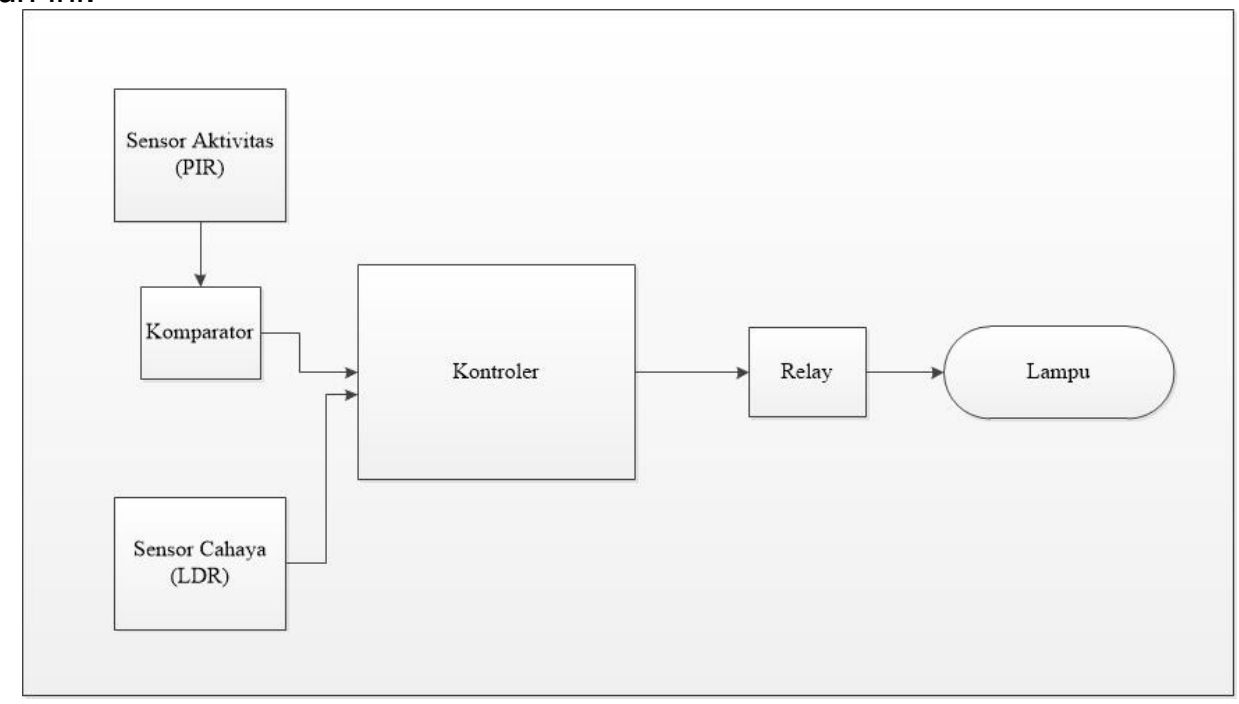

Gambar 6. Blok Diagram Sistem Secara Umum

\subsection{Deskripsi Kerja Sistem}

Ketika ada gerakan/aktivitas manusia di dalam ruangan, maka sensor PIR akan mendeteksi aktivitas tersebut (Otomo, 2013). Output dari modul sensor PIR ini berupa tegangan sebesar $3,3 \mathrm{~V}$, yang selanjutnya tegangan tersebut dialirkan ke komparator agar tegangan menjadi $5 \mathrm{~V}$.

Setelah sensor PIR mendeteksi gerakan, sensor LDR akan memberitahu intensitas cahaya di dalam ruangan. Selanjutnya kontroler akan mengambil keputusan perlu tidaknya lampu dihidupkan, meskipun sensor PIR telah mendeteksi adanya gerakan/aktivitas manusia. Semua output dari sensor selanjutnya diproses oleh kontroler yang terdiri dari beberapa IC (IntegratedCircuit), output dari hasil proses tersebut berupa perintah untuk menghidupkan atau mematikan lampu ruangan dengan relay sebagai saklar otomatisnya. 


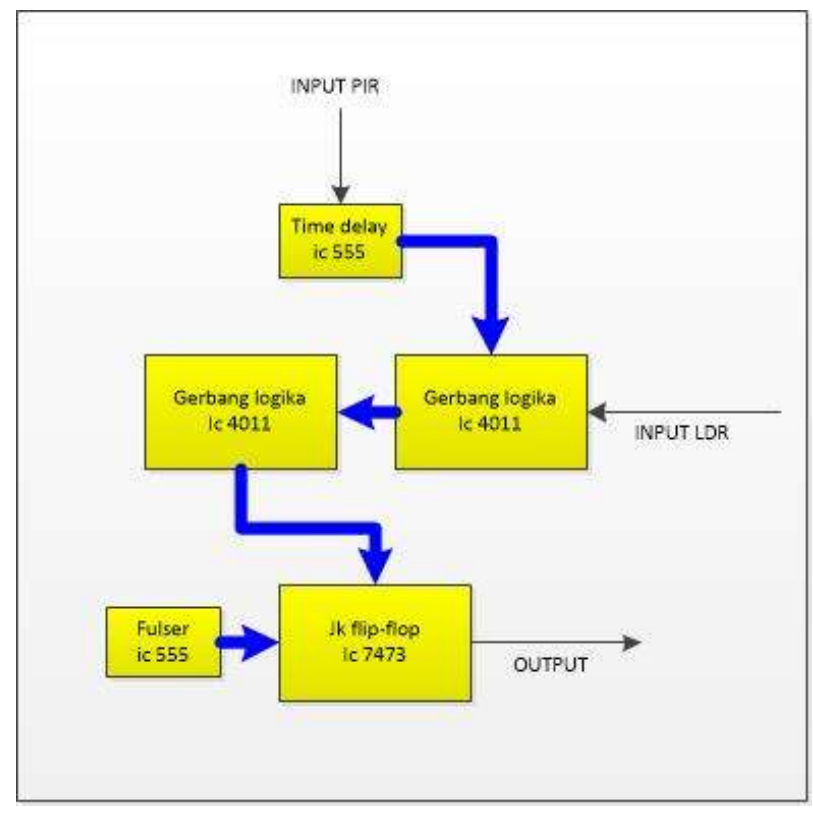

Gambar 7. Blok Diagram Kontroler

\section{SIMULASI DAN PENGUKURAN}

Bab ini membahas hasil simulasi dan pengukuran dari semua perangkat sistem yang telah dirancang.

\subsection{Simulasi dan Pengukuran Karakteristik Catu Daya}

Catu daya yang digunakan berjenis Switching Voltage Regulator dengan keluaran tegangan sebesar $5 \mathrm{~V}$ dan keluaran arus maksimum sebesar $1 \mathrm{~A}$.

a. Tujuan Pengukuran

1. Mengetahui kestabilan tegangan output akibat perubahan beban

2. Mengetahui tegangan ripple

b. Setup Pengukuran

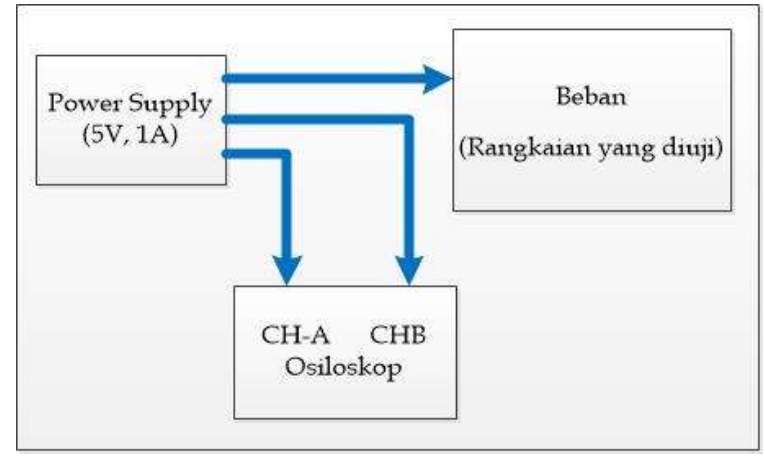

\section{Gambar 8. Blok Diagram Pengukuran Karakteristik PowerSupply}

c. Hasil Pengukuran

Pengukuran dilakukan dalam 2 tahap, yakni tahap pertama dilakukan untuk mengetahui karateristik powersupply tanpa beban, sedangkan tahap kedua dilakukan 
dengan menguji karakteristik powersupply jika diberikan bebanrangkaian. Hasil yang didapat ditampilkan dalam Gambar 9 dan 10 di bawah ini.

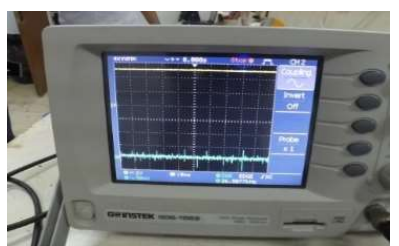

Gambar 9. Foto Bentuk Gelombang Tegangan Keluaran dan Tegangan RipplePowerSupply Tanpa Beban

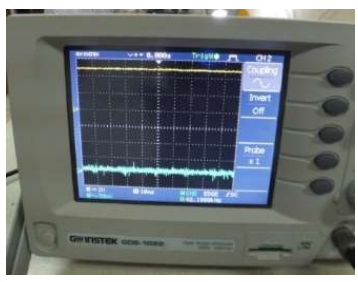

Gambar 10. Foto Bentuk Gelombang Tegangan Keluaran dan Tegangan RipplePowerSupply Dengan Beban Rangkaian

d. Analisa

Pada saat tanpa beban powersupply mengeluarkan tegangan tetap sebesar $5 \mathrm{~V}$ dan tegangan ripple sekitar $5 \mathrm{mV}$, sedangkan pada saat diberikan bebanrangkaian terjadi penurunan tegangan menjadi 4,9V dan tegangan ripple-nya naik menjadi $10 \mathrm{mV}$. Besarnya frekuensi yang terukur di tegangan ripple sebesar 26,5 KHz merupakan frekuensi switching dari powersupply yang dipakai. Performansi tersebut tidak terlalu berpengaruh pada hasil akhir sistem kendali yang dibuat karena masih dalam tarap wajar nilai logika level TTL.

\subsection{Simulasi dan Pengukuran Karakteristik Sensor Aktivitas}

Untuk mendeteksi aktivitas manusia yang berada di dalam ruanganlaboratorium, digunakan sensor aktivitas berupa PIR (Passive Infrared Receiver) dengan jenis HC-SR501 memakai catu daya $5 \mathrm{~V}$.

a. Tujuan

1. Mengetahui karakteristik tegangan keluaran sensor akibat perubahan jarak detektor.

2. Mengetahui tegangan valid output sensor.

b. Setup Pengukuran

Persiapan awal dilakukan dengan memasang sensor PIR di langit-langit ruangan.

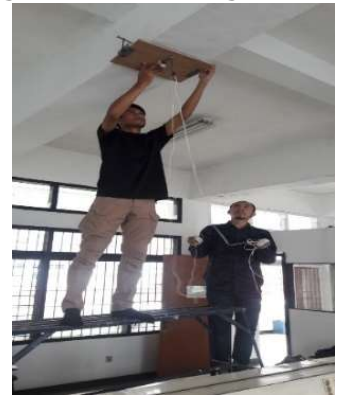

Gambar 11. Foto Persiapan Pengukuran Karakteristik Sensor

MIND- 87 
Setelah sensor PIR HC-SR501 terinstal di langit-langit ruangan dan rangkaian level translator terhubung ke sensor PIR dan catu daya maka disusunlah setup pengukuran sebagai berikut:

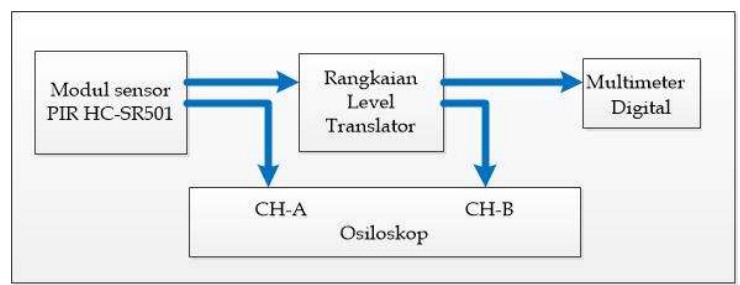

Gambar 12. Blok Diagram Setup Pengukuran Sensor Dan Level Translator

Hasil Pengukuran dan Analisa

Tabel 3. Tabel Hasil Pengukuran Karakteristik Sensor PIR

\begin{tabular}{|c|c|c|c|c|c|c|c|}
\hline \multirow[t]{2}{*}{ No } & \multicolumn{3}{|c|}{ Diukur } & \multicolumn{2}{|c|}{ Dihitung } & \multirow[b]{2}{*}{$\begin{array}{c}\text { Tegangan } \\
\text { keluaran } \\
\text { sensor } \\
\text { PIR, } \\
V_{s} \text { (volt) }\end{array}$} & \multirow[t]{2}{*}{ Keterangan Aktivitas } \\
\hline & $\mathrm{Jam}$ & $\mathrm{x}(\mathrm{cm})$ & $y(\mathrm{~cm})$ & $\theta$ & $\mathrm{r}(\mathrm{cm})$ & & \\
\hline 1. & $11: 00: 00$ & 155 & 232 & 26,4 & 412,4 & 0 & $\begin{array}{c}\text { Tidak ada aktivitas, tidak } \\
\text { ada praktilkan }\end{array}$ \\
\hline 2. & $11: 00: 01$ & 177 & 232 & 37,3 & 291,8 & 3.3 & Praktikan masuk \\
\hline 3. & $11: 00: 02$ & 254 & 232 & 47,6 & 344 & 3.2 & Alktivitas praktikan \\
\hline 4. & $11: 00: 05$ & 303 & 232 & 52,6 & 381,6 & 0 & Alktivitas prakttikan \\
\hline 5. & $11: 00: 06$ & 317 & 232 & 53,8 & 392,8 & 0 & Aktivitas praktikan \\
\hline 6. & $11: 00: 09$ & 232 & 232 & 45,0 & 328,1 & 3,3 & Aktivitas praktikan \\
\hline 7. & $11: 00: 10$ & 245 & 232 & 46,6 & 337,4 & 3,3 & Aktivitas prakttikan \\
\hline 8. & $11: 00: 12$ & 95 & 232 & 22,3 & 250,7 & 0 & Aktivitas praktikan \\
\hline 9. & $11: 37: 15$ & 281 & 232 & 50,5 & 364,4 & 0 & Aktivitas praktikan \\
\hline 10. & $11: 40: 17$ & 294 & 232 & 51,7 & 374,5 & 0 & Aktivitas praktikan \\
\hline 11. & $11: 44: 19$ & 257 & 232 & 47,9 & 346,2 & 3.3 & Aktivitas praktikan \\
\hline 12. & $11: 48: 21$ & 274 & 232 & 49,7 & 359 & 0 & Aktivitas praktikan \\
\hline 13. & $11: 51: 22$ & 341 & 232 & 55,8 & 258,9 & 0 & Alktivitas praktikan \\
\hline 14. & $11: 00: 00$ & 155 & 232 & 26,4 & 258,9 & 3,3 & Aktivitas prakttikan \\
\hline 15. & $11: 00: 01$ & 177 & 232 & 37,3 & 291,8 & 3,3 & Aktivitas praktikan \\
\hline 16. & $11: 00: 02$ & 303 & 232 & 52,6 & 381,6 & 3,2 & Aktivitas praktikan \\
\hline 17. & $11: 00: 06$ & 317 & 232 & 53,8 & 392,8 & 0 & Aktivitas prakttikan \\
\hline 18. & $11: 00: 08$ & 232 & 232 & 45,0 & 328,1 & 3,2 & Aktivitas praktikan \\
\hline 19. & $11: 00: 09$ & 254 & 232 & 47,6 & 344 & 3,2 & Aktivitas praktikan \\
\hline 20. & $11: 00: 11$ & 245 & 232 & 46,6 & 337,4 & 0 & Aktivitas praktikan \\
\hline 21. & $11: 00: 12$ & 95 & 232 & 22,3 & 250,7 & 0 & Aktivitas praltikan |V \\
\hline 22. & $11: 00: 14$ & 254 & 232 & 47,6 & 344 & 0 & Aktivitas praktikan \\
\hline
\end{tabular}

Keterangan:

$\mathrm{X}=$ Jarak dari titik pusat sensor PIR ke objek

$\mathrm{Y}=$ Tinggi dari meja praktek ke Sensor PIR

$\mathrm{R}=$ Panjang sisi miring dari sensor PIR ke objek

$\theta=$ Sudut kemiringan pancaran sensor PIR 


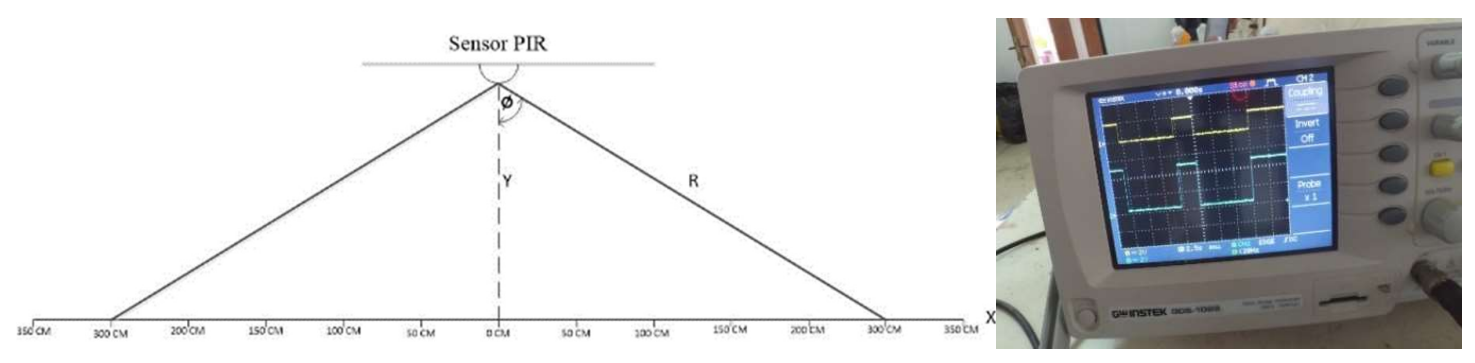

\section{Gambar 13. Foto Bentuk Gelombang Keluaran Sensor PIR Dan Rangkaian Level Translator}

Keterangan Pengukuran:

- Menggunakan osiloskop Gw INSTEK GDS-1022

- $\mathrm{CH}-\mathrm{A}$ terhubung ke keluaran sensor PIR (2V/div)

- $\mathrm{CH}-\mathrm{B}$ terhubung ke keluaran level trans/ator(2V/div)

- Timebase: $2,5 \mathrm{~ms} / \mathrm{div}$

- Coupling: DC

Berdasarkan data pada Tabel 3, sensor telah bekerja sesuai perubahan aktivitas masusia dalam ruangan dengan karakteristik sebagai berikut:

1) Tegangan keluaran minimum dan maksimum pada saat ada aktivitas masing-masing sebesar 2,7 dan 3,3 volt, sedangkan pada saat tidak ada aktivitas adalah 0 volt.

2) Pada jarak $341 \mathrm{~cm}$ sensor PIR HC-SR501 tidak menampilkan hasil yang valid artinya tidak ada perubahan nilai tegangan output antara ada dan tidak ada aktivitas. Jarak maksimal yang dapat dijangkau sensor adalah $340 \mathrm{~cm}$.

3) Waktu delay setelah menerima trigger aktivitas adalah 2,5 detik dan membaca data kembali 7,5 detik setelah waktu aktivitas sebelumnya selesai ditampilkan.

Berdasarkan data pada Gambar 13, selama 7,5 detik delay setelah pembacaan pertama mengakibatkan keluaran sensor tidak valid padahal masih ada aktivitas di dalamruangan yang menunjukan bahwa seharusnya sensor mengeluarkan tegangan sebesar 3,3 volt.

Masalah ini mempengaruhi kesalahan kontroler saat pengambilan keputusan. Dengan kata lain, secara konseptual kontroler menginginkan selama masih ada aktivitasdi dalam ruangan laboratorium keluaran sensor harus tetap bertegangan 3,3 volt. Solusi untuk hal tersebut adalah dengan menambahkan rangkaian validasi sensor PIR yang terdiri dari level translator 7,5 detik monostablemultivibrator, dan rangkaian penentu validasi data sensor PIR.

Berdasarkan data pada Tabel 3 luas cakupan sensor PIR HC-SR501 adalah alas kerucut berbentuk lingkaran dengan jari-jari $300 \mathrm{~cm}$, artinya luas alas kerucutnya adalah 2963,265 $\mathrm{cm}^{2}$. Jadi untuk ruang laboratorium Teknik Elektro Universitas Sangga Buana YPKP dengan luas $65 \mathrm{~m}^{2}$, hanya dibutuhkan 2 sensor PIR HC-SR501 (dengan asumsi tanpa penghalang tiang gedung di dalam ruangan laboratorium). 


\subsection{Pengukuran Karakteristik Rangkaian Validasi Data Sensor PIR}

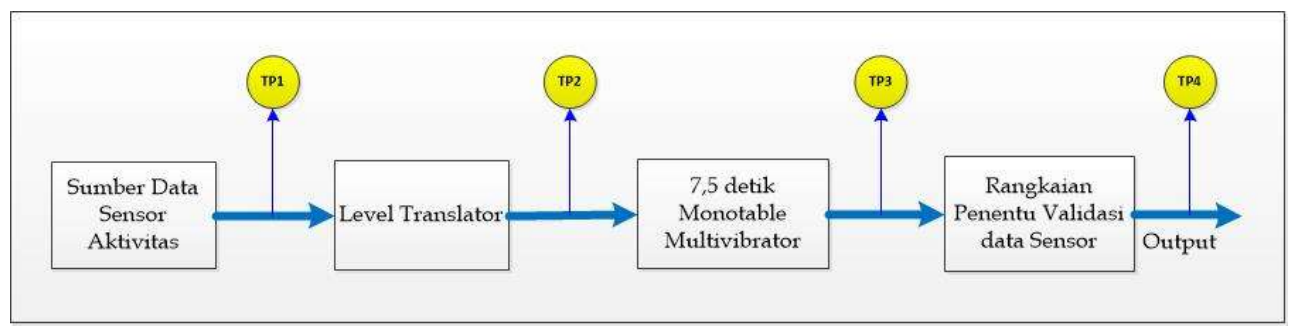

Gambar 14. Blok Diagram Setup Pengukuran Rangkaian Validasi Data Sensor PIR

Untuk membuat simulasi Sumber Data Sensor sesuai Gambar 14, digunakan software Circuit Maker dengan setup sesuai Gambar 15 yang terdapat di halaman selanjutnya.

\begin{tabular}{|c|c|c|c|}
\hline Edit Pulse Data & & & \\
\hline Initial Amplitude : & $0.000 \mathrm{~V}$ & \multirow{3}{*}{$\begin{array}{l}\text { Delay To Start: } \\
\begin{array}{l}\text { Output } \\
\text { C Volts }\end{array}\end{array}$} & $0.000 \mathrm{~s}$ \\
\hline Pulse Amplitude : & $3.300 \mathrm{~V}$ & & \\
\hline Period (=1/rreq) : & $10.00 \mathrm{~S}$ & & $C$ Amps \\
\hline Pulse Width : & $2.500 \mathrm{~S}$ & Properties... & OK \\
\hline Rise Time: & 100.0us & & \\
\hline Fall Time : & 100.0uS & Wave... & Cancel \\
\hline
\end{tabular}

Gambar 15. Data Setup Sumber Data Sensor LDRMenggunakan Simulator CircuitMaker

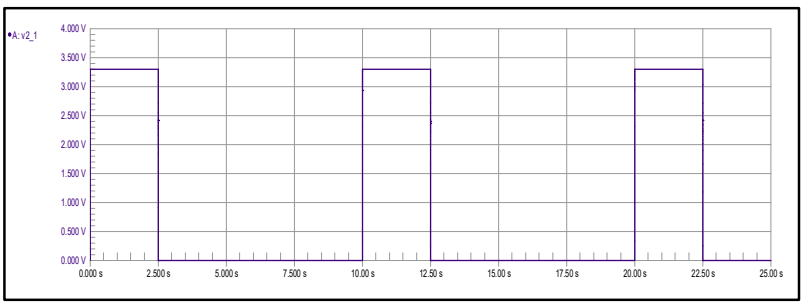

Gambar 16. Bentuk Gelombang Hasil Simulasi Sumber Data Sensor PIR

Nilai perioda sebesar 10 detik merupakan penjumlahan antara delay 2,5 detik dan 7,5 detik, sedangkan nilai pulsewidth adalah nilai aktif delay sensor PIR.

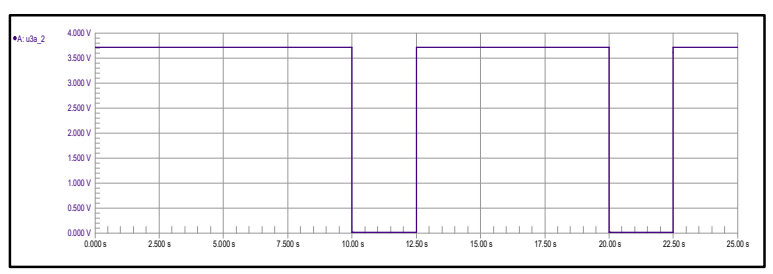

Gambar 17. Bentuk Gelombang Hasil Simulasi 7,5 detik MonotableMultivibrator 


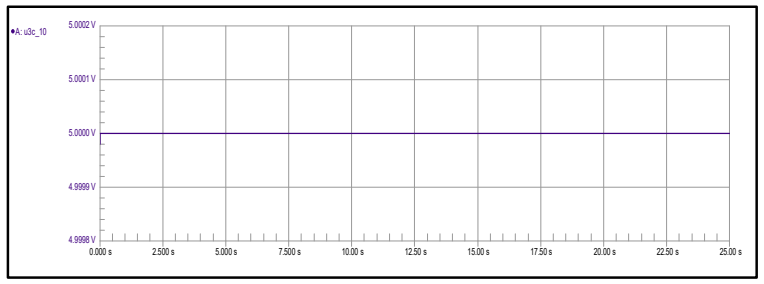

\section{Gambar 18. Bentuk Gelombang Hasil Simulasi Rangkaian Penentu Validasi Data Sensor}

Untuk membuktikan kebenaran hasil simulasi, pengukuran dilakukan dengan bantuan osiloskop pada TP1 dan TP4 untuk masing-masing $\mathrm{CH}-\mathrm{A}$, $\mathrm{CH}-\mathrm{B}$.

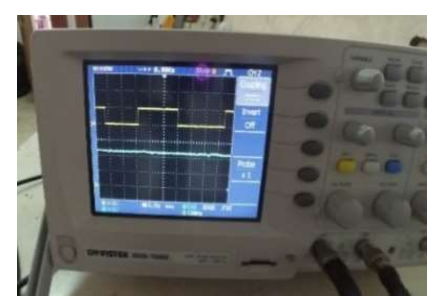

\section{Gambar 19. Bentuk Gelombang Hasil Pengukuran Rangkaian Penentu Validasi data Sensor (CH-B) dan Data sensor PIR HC-SR501(CH-A)}

Berdasarkan simulasi dan pengukuran masalah yang timbul akibat sensor tidak menampilkan data antara 2,5 detik ke 10 detik telah berhasil diselesaikan. Output tegangan stabil di level high 5 volt, cocok dengan karakteristik IC digital yang akan digunakan di unit kontroler. Pengukuran Karakteristik Rangkaian Sensor Cahaya

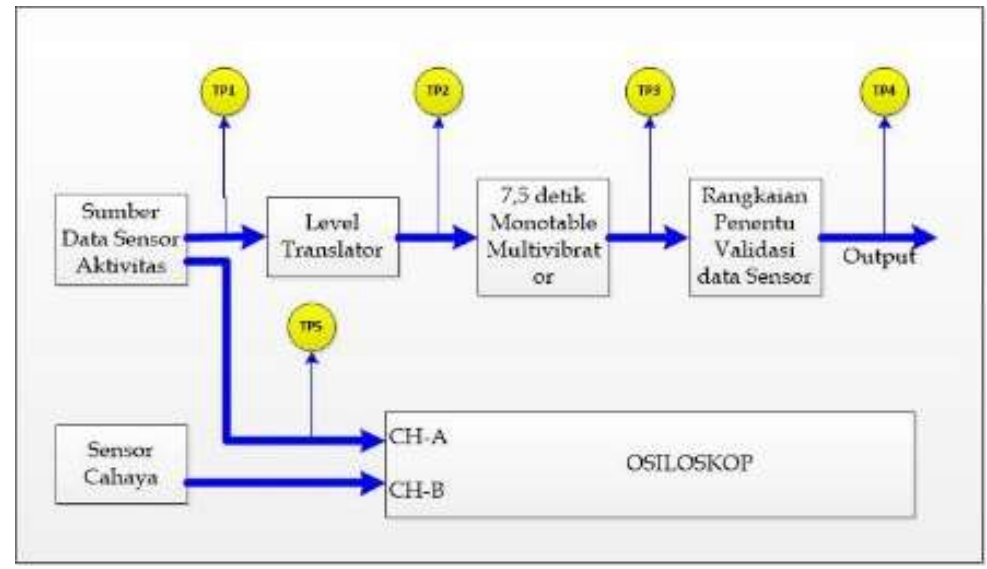

Gambar 20. Blok Diagram Setup Pengukuran Rangkaian Sensor LDR

Pengukuran dilakukan pada TP1 dan TP5 dengan beberapa tahap cahaya. Tahap cahaya yang dimaksud dilakukan dengan cara melakukan pengukuran di sore hari tanpa menyalakan lampu ruangan, menyalakan 1 lampu ruangan, menyalakan 2 lampu ruangan, dan menyalakan 2 lampu ruangan ditambah 1 lampu untuk mengejar nilai iluminasi 400 lux atau 600 lux masingmasing untuk kerja umum dengan detail wajar dan kerja yang lumayan dengan detail kecil (studio, gambar, menjahit). 
Alat yang digunakan adalah osiloskop GwINSTEK GDS-1022, multimeter Fluke 115, lux meter merupakan fasilitas tambahan handphone Xiaomi Redmi Note 5 dengan aplikasi Sensor Box For Android, dan kamera YI Action Camera.

Tabel 4. Setting Dan Hasil Pengukuran Kondisi Pengujian Karakteristik Sensor Cahaya

\begin{tabular}{|c|c|c|c|c|}
\hline No. & Waktu & Tingkat c: & $\begin{array}{l}\text { yang terukur } \\
\text { x) }\end{array}$ & Keterangan pengkondisian tingkat cahaya \\
\hline 1. & $16: 45$ & 9,081 & $\bigcup_{0,00000}^{\infty}$ & Lampu ruangan mati \\
\hline 2. & $16: 47$ & 22,703 & & 1 lampu dinyalakan \\
\hline 3. & $16: 49$ & 87,786 & & 4 lampu dinyalakan \\
\hline 4. & $16: 53$ & 86,273 & & $\begin{array}{l}4 \text { lampu dinyalakan ketika, praktikan } \\
\text { berada dekat sensor }\end{array}$ \\
\hline 5. & $16: 56$ & 304,227 & & $\begin{array}{l}4 \text { lampu dinyalakan ditambah } 1 \text { lampu } \\
\text { dengan jarak tertentu dari sensor cahaya }\end{array}$ \\
\hline 6. & $16: 57$ & 84,759 & & 4 lampu dinyalakan \\
\hline 7. & $17: 24$ & 6,978 & & Lampu ruangan mati \\
\hline 8. & $17: 25$ & 15,135 & & 1 lampu dinyalakan \\
\hline 9. & $17: 28$ & 407,425 & & $\begin{array}{l}4 \text { lampu dinyalakan ditambah } 1 \text { lampu } / \mathrm{a} \\
\text { didekatkan dengan sensor cahaya to to }\end{array}$ \\
\hline
\end{tabular}

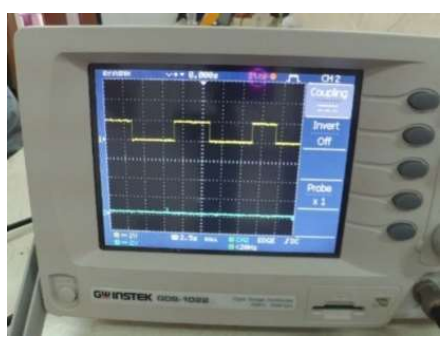

Gambar 21. Foto Bentuk Gelombang Keluaran Sensor PIR (CH-A gambar atas) dan Keluaran Sensor LDR dalam Keadaan Cahaya Terang (CH-B gambar bawah) 


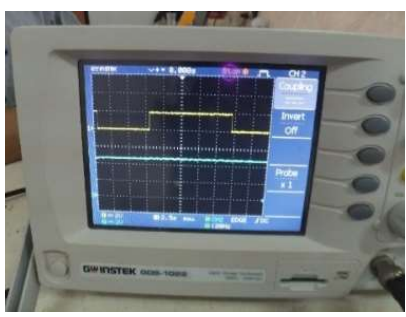

\section{Gambar 22. Foto Bentuk Gelombang Keluaran Sensor PIR (CH-A gambar atas) dan Keluaran Sensor LDR dalam Keadaan Cahaya Gelap (CH-B gambar bawah)}

Berdasarkan data pada Tabel 4 disesuaikan dengan nilai standar tingkat iluminansi maka nilai dibawah 100 lux dikatagorikan gelap dan diatasnya dikatagorikan terang. Nilai 100 Lux diperuntukan bagi penglihatan biasa dan 200 lux diperuntukkan bagi kerja kasar detail besar. Gambar 21 diuji pada saat praktikan di dalam ruangan laboratorium dengan nilai iluminansi sebesar 304,227 lux, sedangkan Gambar 22 diuji pada saat praktikan di dalam ruangan laboratorium dengan nilai iluminansi sebesar 84,759 lux. Pada kondisi tersebut masing-masing sensor baik sensor PIR dan sensor LDR telah menunjukan nilai yang benar sesuaikeinginan (gelap output sensor LDR berlogika high, terang output sensor LDR berlogika low). Pengukuran Karakteristik Rangkaian Kontroler dan Driver.

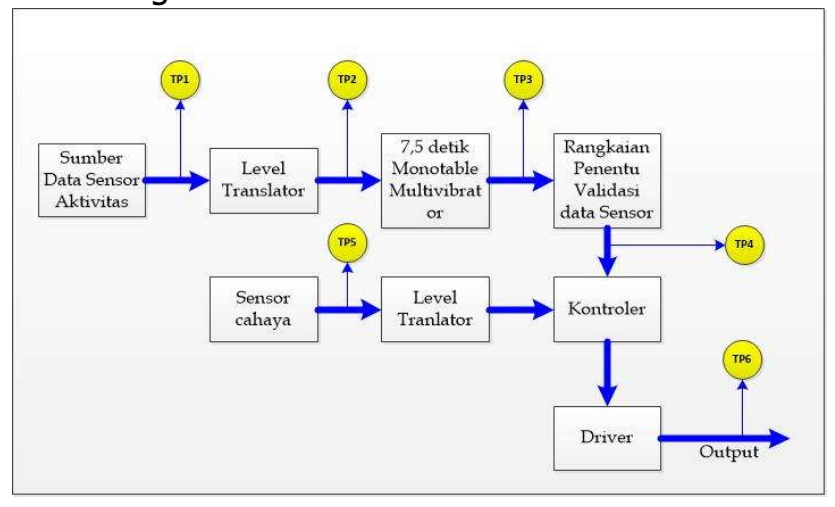

\section{Gambar 23. Blok Diagram Setup Pengukuran Rangkaian Kontroler dan Driver}

Pengukuran dilakukan di titik pengukuran TP1, TP5, TP6 dengan menggunakan alat osiloskop dualtrace untuk TP1 dan TP5 dan multimeter digital di TP6. Hasil yang didapat ditunjukkan pada Tabel 5 di bawah ini.

Beberapa kondisi yang diperoleh pada saat pengukuran adalah lampu nyala permanen, lampu mati permanen, lampu berkedip terus menerus, lampu berkedip sesaat. Lampu berkedip terus menerus dan lampu berkedip sesaat tidak dikehendaki dalam implementasinya. Kondisi lampu berkedip terus menerus diakibatkan sensor LDR tidak menerima cahaya secara fokus. Solusi untuk hal tersebut dilakukan dengan menambahkan media selubung untuk sensor. Sedangkan kondisi lampu nyala padam sesaat kemudian nyala permanen diakibatkan karena adanya transien transisi nilai logika. Solusinya adalah dengan menambahkan rangkaian SchmidtTrigger pada rangkaian kontroler. Seperti terlihat pada gambar di bawah ini. 

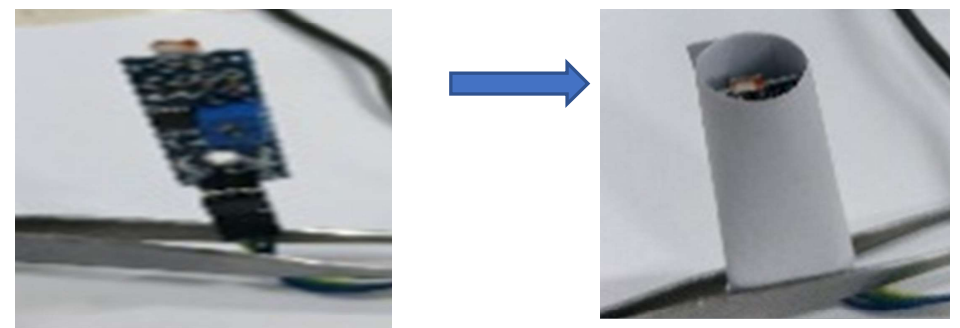

\section{Gambar 24. Foto Penanggulangan Masalah Beberapa Kondisi Pengukuran Karakteristik Rangkaian Kontroler dan Driver}

Setelah dilakukan perbaikan performansi kontroler dan sensor akhirnya sistem yang dirancang dapat beroperasi dengan baik, yakni lampu mati permanen bila cahaya terang atau tidak ada aktivitas, lampu menyala bila cahaya gelap dan ada aktivitas.

Tabel 5. Flicker Lampu Terus Menerus

\begin{tabular}{|c|c|c|}
\hline $\begin{array}{c}\text { Foto hasil pengukur-an di } \\
\text { TP6 }\end{array}$ & $\begin{array}{c}\text { Foto hasil pengukuran di TP } 1 \\
\text { dan TP5 }\end{array}$ & Keterangan \\
\hline & aten & $\begin{array}{l}\text { - Ada aktivitas } \\
\text { - Cahaya gelap } \\
\text { - Tegangan output driver } \\
220 \text { volt AC } \\
\text { - Lampu menyala }\end{array}$ \\
\hline & $\tan -n=$ & $\begin{array}{l}\text { - Lampu nyala padam } \\
\text { - Tegangan output driver } \\
\text { turun naik } \\
\text { - Ada Altivitas }\end{array}$ \\
\hline & te & $\begin{array}{l}\text { - Lampu berkedip sesaat } \\
\text { kemudia menyala } \\
\text { permanen } \\
\text { - Ada aktivitas } \\
\text { - Tegangan turun naik } \\
\text { sebentar keudian } \\
\text { bermilai } 220 \text { volt AC } \\
\text { permanen }\end{array}$ \\
\hline & & $\begin{array}{l}\text { - Ada ahtivitas } \\
\text { - Lampu mati } \\
\text { - Tegangan menuju 0 volt } \\
\text { AC }\end{array}$ \\
\hline
\end{tabular}

\section{KESIMPULAN DAN SARAN}

\subsection{Kesimpulan}

Kesimpulan dari proses perancangan sistem otomasi lampu ruang laboratorium Teknik Elektro Universitas Sangga Buana YPKP ini adalah sebagai berikut:

1. Berdasarkan hasil simulasi dan pengujian yang telah dilakukan, sistem yang dibuat mampu menghidupkan atau mematikan lampu ruangan secara otomatis berdasarkan keberadaan manusia dengan mempertimbangkan intensitas cahaya di dalam ruangan. 
2. Sensor PIR HC-SR501 dapat mendeteksi gerakan manusia dengan baik sejauh $365,3 \mathrm{~cm}^{2} /$ sensor.

3. Sensor LDR yang digunakan mampu mendeteksi intensitas cahaya dengan baik, tetapi sensor perlu selubung untuk memfokuskan pembacaan intensitas cahaya di dalam ruangan.

\subsection{Saran}

Berdasarkan dari hasil pengujian yang telah dilakukan, dapat diberikan saran sebagai berikut:

1. Untuk kedepannya sistem dapat ditambahkan buzzer sebagai penanda apabila lampu putus (rusak).

2. Penempatan sensor perlu diperhatikan, terlebih untuk sensor LDR agar pembacaan sensor lebih optimal.

3. Pemilihan sensor PIR yang lebih peka/sensitif dengan delay time yang lebih sedikit, apabila akan diimplementasikan pada ruangan yang tingkat aktivitasnya tinggi.

\section{DAFTAR PUSTAKA}

Fallo, F. C. (2017) Perancangan Prototype Sistem Otomasi Berbasis Mikrokontroler Untuk Lampu Penerangan Ruangan Di UAJY, Tugas Akhir.

Otomo, G. (2013) 'Pendeteksian Ada Tidaknya Orang Di Dalam Ruangan', Jurnal Fisika Unand.

Sutono, S. S. (2015) 'Perancangan sistem aplikasi otomatisasi lampu penerangan menggunakan sensor gerak dan sensor cahaya berbasis arduino uno (atmega 328)', Majalah IImiah UNIKOM. doi: 10.34010/miu.v12i2.25.

Toyib, R., Bustami, I. and Abdullah, D. (2019) 'PENGGUNAAN SENSOR PASSIVE INFRARED RECEIVER ( PIR ) UNTUK MENDETEKSI GERAK BERBASIS SHORT MESSAGE SERVICE', Jurnal Pseudocode. 